\title{
Kliniğimizde 10 Yıllık Endometrium Kanser Yönetimi
}

\section{0-Year Endometrium Cancer Management in Our Clinic}

\author{
Emine Türen Demir ${ }^{1}$, Ali Acar ${ }^{1}$
}

${ }^{1}$ Necmettin Erbakan Üniversitesi, Meram Tıp Fakültesi, Kadın Hastalıkları ve Doğum

Yazışma Adresi: Emine Türen Demir, Necmettin Erbakan Üniversitesi, Meram Tıp Fakültesi, Kadın Hastalıkları ve Doğum Anabilim Dalı, Konya, Türkiye Kabul Tarihi/Accepted: 3 Aralık 2019 Anabilim Dalı, Konya, Türkiye e-posta: eturen1@hotmail.com

Geliş Tarihi/Received: 26 Ekim 2019

Öz

Amaç: Endometriyum kanseri kadın genital sisteminin en sık malignitesi olup, kadınlarda görülen kanserler arasında dördüncü sırada yer almaktadır. Amacımız jinekolojik onkoloji kliniğimizdeki endometriyum kanserli olgularının cerrahi tedavi ve sonuçlarını paylaşmaktır.

Hastalar ve Yöntem: Bu çalışmada 2009-2019 yılları arasında kliniğimizde endometrium kanseri tanısı alıp aynı cerrahi ekip tarafından opere edilen 164 hastanın dosyaları retrospektif olarak incelenip, hastaların klinik, cerrahi ve histopatolojik özellikleri ile ilgili sonuçlar paylaşılmıştır. Patoloji sonucu sarkom gelen 4 hasta, tamamlayıcı cerrahi yapılan 7 hasta, ikinci bir primer tümörü olan 1 hasta çalışmaya dahil edilmemiştir.

Bulgular: Çalışmamıza dahil edilen hastaların ortalama yaşı 61,3 ortalama vücut kitle indeksleri 25,8 idi. Hastaların postoperatif patoloji sonuçlarına göre; ortalama tümör büyüklüğü $3,4 \mathrm{~cm}$, toplanan ortalama lenf nodu sayısı 28,8 idi. 19 hastada lenf nodu metastazı izlendi ve metastazların hepsi pelvik lenf nodlarında idi. Hastaların \% 81'inde endometrioid tip adenokarsinom olduğu görüldü. 81 hastada $(\% 49,4)$ myometria invazyon > $\% 50$ idi. 20 hastada (\%12.2) servikal tutulum, 11 hastada $(\% 6,7)$ adneksiyal tutulum, 28 hastada $(\% 17,1)$ lenfovaskuler alan invazyonu mevcuttu. 76 hasta $(\% 46,3)$ grade 1,61 hasta $(\% 37,2)$ grade 2,19 hasta $(\% 11,6)$ grade $3^{\prime}$ 'idi. Hastaların 2009 FIGO sistemine göre evlemesi yapıldığında 70 hasta $(\% 42,7)$ evre $1 \mathrm{~A}, 58$ hasta $(\% 35,4)$ evre $1 \mathrm{~B}, 12$ hasta $(\% 7,3)$ evre 2,3 hasta $(\% 1,8)$ evre $3 \mathrm{~A}, 17$ hasta $(\% 10,4)$ evre $3 \mathrm{C} 1,4$ hasta $(\% 2,4)$ evre 4 idi.

Sonuc: Endometrium kanseri en sık görülen jinekolojik kanser olup, erken dönemde bulgu vermesi sonucu genellikle erken evrede yakalanmaktadır. Hastalığın riskini değerlendirmede tümör boyutu, miyometrial invazyon derinliği, histopatolojik grade kullanılmaktadır ancak özellikle yüksek evre hasta sayının daha fazla olduğu çalışmalar, risk belirlemede daha faydalı olacaktır.

Anahtar Kelimeler: Endometriyum kanseri, lenf nodu diseksiyonu, cerrahi evre, prognoz, grade, miyometrial invazyon

\section{Abstract}

Aim: Endometrial cancer is the most common malignancy of the female genital tract and the fourth leading cancer among women. Our aim is to share the surgical treatment and results of endometrial cancer cases in our gynecological oncology clinic.

Patients and Methods: In this study, the records of 164 endometrial cancer patients operated by the same surgical team between 2009-2019 were reviewed retrospectively. The clinical, surgical and histopathological features of the patients are presented here. Four patients who had sarcoma as a result of pathology, 7 patients who underwent complementary surgery and 1 patient with a second primary tumor were not included in the study.

Results: The mean age of the patients included in our study was 61.3 and the mean body mass index was 25.8. According to the postoperative pathology results; mean tumor size was $3.4 \mathrm{~cm}$ and mean number of collected lymph nodes was 28.8. Lymph node metastasis was observed in 19 patients and all of the metastases were in pelvic lymph nodes. Endometrioid type adenocarcinoma was seen in $81 \%$ of the patients. Myometrial invasion $>50 \%$ in 81 patients $(49.4 \%)$. Twenty patients $(12.2 \%)$ had cervical involvement, 11 patients $(6.7 \%)$ had adnexal involvement and 28 patients $(17.1 \%)$ had lymphovascular area invasion. 76 patients $(46.3 \%)$ were grade 1,61 patients $(37.2 \%)$ were grade 2,19 patients $(11.6 \%)$ were grade 3 . When the patients were staging according to the FIGO system in $2009,70(42.7 \%)$ stage $1 \mathrm{~A}, 58(35.4 \%)$ stage $1 \mathrm{~B}, 12(7.3 \%)$ stage $2,3(1.8 \%)$ stage $3 \mathrm{~A} 17$ patients $(10.4 \%)$ were stage $3 \mathrm{C} 1$ and 4 patients $(2.4 \%)$ were stage 4.

Conclusion: Endometrial cancer is the most common gynecological cancer, and it is usually diagnosed at an early stage as a result of early signs. Tumor size, depth of myometrial invasion and histopathologic grade are used to evaluate the risk of the disease, but studies with a higher number of high stage patients will be more useful in determining the risk.

Key words: Endometrial cancer, lymph node dissection, surgical stage, prognosis, grade, myometrial invasion

Atıf yapmak için: Demir Türen E, Acar A. Kliniğimizde 10 Yıllık

Endometrium Kanser Yönetimi. Selcuk Med J 2021;37(2): 166-171

Açıklama: Yazarların hiçbiri, bu makalede bahsedilen herhangi bir ürün, aygıt veya ilaç ile ilgili maddi çıkar ilişskisine sahip değildir. Araştırma, herhangi bir dış organizasyon tarafından desteklenmedi. Yazarlar çalış̧manın birincil verilerine tam erişim izni vermek ve derginin talep ettiği takdirde verileri incelemesine izin vermeyi kabul etmektedirler.

“This article is licensed under a Creative Commons Attribution-NonCommercial 4.0 International License (CC B Y-NC 4.0)" 


\section{GíRiş}

Endometrium kanseri gelişmiş ülkelerde en sık görülen jinekolojik kanserdir. Amerikan kanser derneği 2019 yılında Amerika Birleşik Devletleri'nde tahmini olarak 61,880 vakanın yeni tanı alacağını ve 12,160 kadının endometrium kanseri nedeni ile öleceğini bildirmiştir (1). 2014 verilerine göre Türkiye' de endometrial kanser görülme oranı \% 5,4'dür (2). Gün geçtikçe endometrial kanser sıklığında belirgin bir artış olduğu izlenmekte olup bu da obezitede artış, yaşam süresinin uzaması ve meme kanserinde tamoksifen kullanımında artış ile ilişkilendirilmektedir. Endometrium kanserinde tanımlanan en önemli risk faktörleri obezite, uzun süreli endojen veya eksojen hiperöstrojenizm (polikistik over sendromu, tamoksifen tedavisi, anovülasyon, östrojen replasman tedavisi, nulliparite), hipertansiyon ve diabetes mellitus'tur. Hastaların büyük çoğunluğu postmenapozal kanama ile doktora başvurmaktadır. Asemptomatik kadınlarda taramayı destekleyen kanıtlar bulunmamaktadır. Tarama sadece Lynch sendromu (Herediter NonPolipozis Kolorektal Kanser) gibi yüksek risk faktörü bulunan gruba önerilmektedir. Endometrial kanser tedavisinin temelini histerektomi ve bilateral salpingooferektomi oluşturmaktadır. Hastalar genellikle erken evrede tanı almakta ve iyi prognoza sahip olmaktadırlar.

Biz bu çalışmada 10 yıllık süreçte jinekoloji kliniğimizde endometriyum kanseri tanısıyla opere ettiğimiz hastaları değerlendirerek endometrium kanserinde prognoza etki eden faktörleri incelemeyi amaçladık.

\section{HASTALAR VE YÖNTEM}

Çalışmaya Necmettin Erbakan Üniversitesi Tıp Fakültesi Girişimsel Etik Kurulu'nun 2020/2697 sayılı kararı ile onay alınmıştır. Bu çalışmaya 20092019 yılları arasında kliniğimizde endometrium kanseri tanısı alıp opere edilen hastalar dahil edilmiştir. Çalışmaya dahil etme kriterleri; hastaların endometrium kanser tanısını kliniğimizde alıp, aynı cerrahi ekip tarafından opere edilmeleri olup, dışlama kriterleri postoperatif patoloji rapor sonuçlarının sarkom gelmesi, ikinci bir primer tümörün olması ve sonradan evreleme cerrahisi yapılmasıdır. Bunlar sonucunda çalışmaya 164 hasta dahil edilmiştir. Veriler uygun ICD kodları kullanılarak hastane arşivinden dosya incelemesi ve patoloji raporlarının incelenmesi ile elde edilmiştir. Preoperatif endometrial örnekleme sonucu endometrial karsinom gelen tüm hastalar preoperatif dönemde anestezi ile konsulte edilmiş ve ASA (american society of anesthesiologists) sınıflandırması yapılmıştır. Hastalar ameliyat gününden bir gün önce hospitalize edilmiş, barsak temizliği yapılmış, gerekli kan ürünleri hazırlanmıştır. Hastanemizde frozen sonuçlarının gecikmesi ve bazı dönemlerde frozen çalışılamaması nedeni ile cerrahi planlanmış olan tüm hastalara total histerektomi ve bilateral salpingooferektomi, lenf nodu diseksiyonu, omentum örneklemesi yapılmıştır. Palpable lenf nodu bulunmayan hastalarda lenf nodu diseksiyonu lenf nodu örneklemesi şeklinde yapılmıştır. Hastaların tamamına dren koyulmuş, drenler postoperatif birinci günde çekilmiştir. Tüm hastalara postoperatif dönemde anti-embolik çorap giydirilmiş ve 1 ay süreyle anti-embolik çorap kullanımına devam etmeleri önerilmiştir. Tüm hastalar erken dönemde mobilize edilmiştir. Hastalar taburculuk sonrası 1. ve 6. hafta sonra kontrole çağırılmış, kesi yeri muayenesi, ultrasonografileri yapılmıştır. Tüm hastaların postoperatif patoloji sonuçları değerlendirilip, onkoloji birimine konsültasyonları istenmiştir.

Hastaların demografik özellikleri, intraoperatif komplikasyon olup olmadığı, intraoperatif kanama miktarı, transfüzyon yapılıp yapılmadığı, preoperatif ve postoperatif patoloji sonuçları kaydedilmiştir. Hastalar FIGO 2009 kriterlerine göre evlendirilmiştir.

\section{BULGULAR}

Çalışmamıza dahil edilen hastaların ortalama yaşı 61,3 olup 36-85 arasında değişmekte idi. Hastaların ortalama vücut kitle indeksleri 25,8 , ortalama çocuk sayısı 3,1 olarak saptandı. Hastaların ortalama 3,1 gün (3-10 gün) hastanede kaldığı görüldü. Ortalama kanama miktarı $500 \mathrm{ml}$ olarak tespit edildi ve hastaların $\% 9,1$ ' ine kan transfüzyonu yapıldığı görüldü (Tablo 1). 164 hastanın 5 tanesinde (\%3) komplikasyon geliştiği, bunlardan birinde obturator alanda kanama olduğu, ikisinde mesane yaralanması olduğu, 2 tanesinde de kesi yeri enfeksiyonu geliştiği görüldü. Hastaların postoperatif patoloji sonuçlarına göre; hastalarda ortalama tümör büyüklüğü $3,4 \mathrm{~cm}(2,5-17$ $\mathrm{cm})$ idi. 9 hastada $(\% 5,5)$ endometrium kanserinin

Tablo 1. Demografik Özellikler

\begin{tabular}{lll}
\hline & Ortalama & Aralık \\
\hline Yaş & $61,3 \pm 9,5$ & $36-85$ \\
Bmi & $25,8 \pm 2,1$ & $19-32$ \\
Parite & $2,7 \pm 0,7$ & $0-4$ \\
Hospitalizasyon Süresi & $3,1 \pm 1,6$ & $3-10$ \\
Toplanan Lenf Nodu Sayısı & $28,8 \pm 13,6$ & $10-89$ \\
Tümor Boyutu & $3,4 \pm 1,8$ & $2,5-8$ \\
\hline
\end{tabular}


Tablo 2. Demografik Özellikler

\begin{tabular}{|c|c|}
\hline Özellik & Değer \\
\hline \multicolumn{2}{|l|}{ Histolojik Tip } \\
\hline Endometrioid & $\% 81,1$ \\
\hline \multicolumn{2}{|l|}{ Non- endometrioid } \\
\hline Berrak hücreli & $\% 2,4$ \\
\hline Seröz & $\% 8,5$ \\
\hline Müsinöz & $\% 0,6$ \\
\hline Mixt Tip & $\% 6,7$ \\
\hline \multicolumn{2}{|l|}{ Evre } \\
\hline $1 \mathrm{~A}$ & $\% 42,7$ \\
\hline 1B & $\% 35,4$ \\
\hline 2 & $\% 7,3$ \\
\hline $3 \mathrm{~A}$ & $\% 1,8$ \\
\hline $3 \mathrm{C} 1$ & $\% 10,4$ \\
\hline 4 & $\% 2,4$ \\
\hline \multicolumn{2}{|l|}{ Grade } \\
\hline 1 & $\% 46,3$ \\
\hline 2 & $\% 37,2$ \\
\hline 3 & $\% 11,6$ \\
\hline \multicolumn{2}{|l|}{ Myometrial İnvazyon } \\
\hline$>1 / 2$ & $\% 49,4$ \\
\hline$<1 / 2$ & $\% 37,2$ \\
\hline Yok & $\% 11$ \\
\hline Servikal Tutulum & $\% 12,2$ \\
\hline Pozitif Sitoloji & $\% 4,3$ \\
\hline Adneks Tutulumu & $\% 6,7$ \\
\hline Lenf Nodu Metastazı & $\% 11,6$ \\
\hline Paraaortik & 0 \\
\hline Pelvik & $\% 100$ \\
\hline LVAI & $\% 17,1$ \\
\hline
\end{tabular}

polip zemininden geliştiği rapor edilmişti. Ortalama 28,8 lenf nodu (10-89) toplanmış olduğu görüldü. 19 hastada lenf nodu metastazı izlendi, metastazların hepsi pelvik lenf nodlarında idi. Histolojik tiplere bakıldığında; 134 hastada endometrioid tip, 4 hastada berrak hücreli tip, 11 hastada mix tip, 1 hastada müsinöz tip, 14 hastada seröz tip olduğu izlendi. 61 hastada $(\% 37,2)$ myometrial invazyon $<1 / 2,81$ hastada $(\% 49,4)$ myometrial invazyon $>1 / 2$ idi. 18 hastada (\%11) myometrial invazyon olmadığı görüldü. 20 hastada $(\% 12,2)$ servikal tutulum, 11 hastada $(\% 6,7)$ adneksiyal tutulum, 28 hastada $(\% 17,1)$ lenfovaskuler alan invazyonu mevcuttu.7 hastanın $(\% 4,3)$ sitolojisi malign olarak rapor edilmişti. 76 hasta $(\% 46,3)$ grade 1,61 hasta $(\% 37,2)$ grade 2,19 hasta $(\% 11,6)$ grade 3 ' idi. Hastaların 2009 FIGO sistemine göre evlemesi yapıldığında 70 hasta $(\% 42,7)$ evre $1 \mathrm{~A}, 58$ hasta $(\% 35,4)$ evre $1 \mathrm{~B}, 12$ hasta $(\% 7,3)$ evre 2,3 hasta $(\% 1,8)$ evre 3A, 17 hasta $(\% 10,4)$ evre 3C1, 4 hasta $(\% 2,4)$ evre 4 idi (Tablo 2).

Hastalar 5 yıllık sağkalımı değerlendirmek için 2014 yılı ve öncesi opere olanlar, 2014 yılı sonrası opere olanlar şeklinde ikiye ayrıldığında; 39 hastanın 2014 yılı ve öncesi opere olduğu, bunlardan 4 tanesinin ex olduğu tespit edilmiş ve 5 yıllık sağkalım oranı \% 92 olarak bulunmuştur. Bu hastalardan üç tanesi evre 1 ancak 80 yaş üzerinde, 1 tanesi 68 yaşında ve evre $3 \mathrm{C} 1$ ' dir.

Lenf nodu metastazı ve hastalığın evresine etki eden faktörler incelendiğinde tümör boyutu $>2 \mathrm{~cm}$ olan hastaların \%14' ünde lenf nodu metastazı mevcut olup, \%16'sı ileri evre idi. Tümör boyutu <2 $\mathrm{cm}$ olan hastalarda ise lenf nodu tutulumu $\% 5$, ileri evre hastalık oranı \%11'idi. Myometrial invazyon derecesi > \%50 olan hastaların \%16' sında lenf nodu metastazı mevcut olup, $\% 18,5$ 'i ileri evre idi. Myometrial invazyon derecesi $<\% 50$ olan hastaların $\% 7$ ' sinda lenf nodu metastazı mevcut olup, \%11'i ileri evre idi. Düşük gradeli hastaların \%11'inde, yüksek gradeli hastaların \%16'sında lenf nodu pozitif, düşük

Tablo 3. Lenf nodu tutulumu ve hastalık evresine etki eden faktörler (LVAl:lenfovasküler alan tutulumu)

\begin{tabular}{|c|c|c|c|c|}
\hline & Lenf & ulumu & $\mathrm{Ha}$ & vresi \\
\hline & Oran & P Değeri & Oran & P Değeri \\
\hline Sitoloji & & 0,008 & & 0,001 \\
\hline Pozitif & $\% 43$ & & $\% 86$ & \\
\hline Negatif & $\% 10$ & & $\% 11$ & \\
\hline LVAI & & 0,001 & & 0,001 \\
\hline Pozitif & $\% 7$ & & $\% 39$ & \\
\hline Negatif & $\% 3,5$ & & $\% 9,5$ & \\
\hline Tümör Boyutu & & 0,089 & & 0.476 \\
\hline$>2 \mathrm{~cm}$ & $\% 14$ & & $\% 16$ & \\
\hline$<2 \mathrm{~cm}$ & $\% 5$ & & $\% 11$ & \\
\hline İnvazyon Derecesi & & 0,078 & & 0,166 \\
\hline$>\% 50$ & $\% 16$ & & $\% 18,5$ & \\
\hline$<\% 50$ & $\% 7$ & & $\% 11$ & \\
\hline Grade & & 0,545 & & 0,593 \\
\hline Düşük grade & $\% 11$ & & $\% 10,5$ & \\
\hline Yüksek grade & $\% 16$ & & $\% 15$ & \\
\hline
\end{tabular}


gradeli hastaların \%15'inde ileri evre, yüksek gradeli hastaların \%10,5'inde ileri evre hastalık saptandı ancak bunlar istatistiksel olarak anlamlı bulunmadı $(p>0,05)$.

Lenfovasküler alan tutulumu olan hastaların $\% 7$ sinde lenf nodu metastazı olup, \%39'u ileri evre hastalık idi. Sitoloji pozitif gelen hastalarında \%43'ünde lenf nodu metastazı pozitif olup \%86'sı ileri evre idi. Lenfovasküler alan tutulumu, sitoloji pozitifliği ile lenf nodu metastazı, hastalık evresi arasında istatistiksel olarak anlam bulundu $(p<0,05)$ (Tablo 3$)$.

\section{TARTIŞMA}

Endometrium kanseri meme, akciğer ve kolorektal karsinomdan sonra kadınlarda görülen en sık 4. kanserdir. Kadınlarda kansere bağlı ölümlerde ise 6 . sırayı almaktadır (3). Endometrium kanseri genellikle postmenapozal dönemde görülür ve ortalama görülme yaşı 63' dür (4). 45 yaş altındaki kadınlarda nadir olarak görülmektedir ve bu yaş grubundaki endometrial karsinomlar, ailesel, Lynch sendromuyla ilişkili veya sporadik olabilir. 40 yaş ve daha genç hastalarda sağ kalım 40 yaş üstü hastalara göre daha iyi bulunmuştur (5). Hastaların çoğu obez, hipertansif, postmenapozal kadınlardır. Bizim hasta grubumuzun \%60'ı da benzer şekilde 60 yaş üstü olup, 11 hasta $(\% 6,7) 45$ yaş altındadır. Ayrıca hastaların büyük çoğunluğunun (\%86) BMI değeri 25 üzerindedir.

En sık görülen semptom anormal uterin kanama olup, postmenapozal kanamalarda ve 40 yaş üstü yüksek risk faktörü olan kadınlarda anormal uterin kanama varlığı olması durumunda endometrial kanser açısından uyanık olunmalıdır. Şüpheli durumlarda yapılacak ilk görüntüleme tekniği transvajinal ultrasonografidir. Transvaginal ultrasonografi, endometrial kalınlık için cut-off değeri $5 \mathrm{~mm}$ alındığında yüksek negatif prediktif değere sahip etkili bir testtir (6). Endometrial kalınlık tespit edilmesi halinde endometrial örnekleme yapılmalıdır. Transvajinal ultrason ve endometrial biyopsi kombinasyonunun \%96 negatif prediktif değere sahip olduğu gösterilmiştir (6). Benign gelen örnekleme sonuçlarına rağmen kanamanın devam ettiği durumlarda histereskopi önerilmektedir.

Postmenopozal kanamayı takiben hastalar genellikle erken evrede teşhis edilmektedir ve bu nedenle prognoz genel olarak iyidir. Hastaların \%75' i evre 1-2' de tanı almaktadır ve 5 yıllık survival evre 1-2 için \%74-91, evre 3 için \%57-66, evre 4 için $\% 20$ -26' dır (4,7). Bizim kliniğimizde de literatüre benzer şekilde hastaların \% 78'i erken evre de tanı almış ve erken tanı ve tedavi sonucu 5 yıllık sağ kalımımız \% 92 olarak bulunmuştur. WHO/ uluslararası jinekolojik patoloji derneğinin sınıflandırılmasına göre 7 farklı histopatolojik tip bulunmaktadır. Bunlar, endometrioid karsinom (adenokarsinom varyantları; skuamoz varyant, villoglanduler varyant ve sekretuar varyant), müsinöz adenokarsinom, seröz adenokarsinom, berrak hücreli adenokarsinom, nöroendokrin tümörler, undifferentiated karsinom ve karsinosarkomdur. En sık endometrioid tip (\%80) görülmekte olup, grade 1-2 olanlar genellikle östrojen bağımlı, premalign intraepitelyal endometrial neoplazi sonucu gelişmektedir (8). Seröz ve berrak hücreli karsinom gibi diğer histolojik tipler ise, genetik bir mutasyon sonucu ortaya çıkmaktadır ve tümör baskılayıcı gen p53'teki mutasyonların seröz endometrial kanser gelişiminde önemli bir rol oynadığı gösterilmiştir (9). Seröz adenokarsinomlar genellikle agresif tümörler olup derin miyometrial invazyon ve geniş lenf nodu tutulumu ile seyretmektedir (10). Bizim vakalarımızda da literatüre benzer şekilde en sık endometrioid tip görülmekte olup $(\% 81,1)$, bunların $\%$ 91'i grade 1-2 ve \% 88' i evre 1 olarak rapor edilmiştir. Seröz adenokarsinomların ise \% 17 ' si de yüksek grade ve \% 57'si ileri evre (evre 3-4) olarak gelmiştir. İleri evre olguların \%20' sini de seröz adenokarsinomlar oluşturmaktadır. Seröz adenokarsinomlarda lenfovasküler alan tutulumu \%35,7, lenf nodu tutulumu $\% 42,8$ olarak görülmüştür.

Mayo kriterlerine göre; grade 1-2, miyometrial invazyon $<\% 50$ ve tümör boyutu $<2 \mathrm{~cm}$ olan tümörler düşük riskli kabul edilirken, grade 3 , miyometrial invazyon $>\% 50$ ve tümör boyutu $>2 \mathrm{~cm}$ olan tümörler yüksek riskli olarak kabul edilmektedir (11). Schink et al.(12) evre 1 endometrium kanseri olan hastalarda yaptıkları çalışmalarında, tümör çapı $>2 \mathrm{~cm}$ olan hastalarda \% 15, tümör çapı $<2 \mathrm{~cm}$ olan hastalarda $\%$ 4, tümörün kaviteyi tamamen doldurduğu hastalarda \% 35 lenf nodu metastazı saptamışlardır ve tümör büyüklüğünü, lenf nodu biyopsisi yapılmayan hastalarda önemli bir prognostik faktör olarak belirtmişlerdir. Mariani et al.(11) grade 1-2, myometrial invazyon $<\% 50$, tümör boyutu $<2 \mathrm{~cm}$ olan hastalarda lenf nodu tutulumunun daha az olduğunu raporlamışlardır. Vargas et al.(13) 19,329 hastayı kapsayan çalışmalarında mayo kriterlerine göre düşük riskli olan hasta grubunda lenf nodu metastaz riskini $\% 1,4$, yüksek riskli olan grupta ise $\% 6.4$ olarak bulmuşlardır. Myometrial invazyon dışlandığında ise düşük riskli hasta grubunda lenf nodu metastaz riskini $\% 2,4$, yüksek riskli grupta ise $\% 10,4$ olarak 
bulmuşlardır. Bizim çalışmamızda ise tümör boyutu $>2 \mathrm{~cm}$ olan hastalarda lenf nodu metastaz oranı $\% 14,1$, tümör boyutu $<2 \mathrm{~cm}$ olan hastalarda lenf nodu metastaz oranı $\% 4,5$, miyometrial invazyon derecesi $>\% 50$ olan hastalarda lenf nodu metastaz oranı \%16, miyometrial invazyon derecesi $<\% 50$ olan hastalarda lenf nodu metastazı \% 7,2 olarak bulunmuştur ancak lenf nodu tutulumu ile tümör boyutu, miyometrium invazyon derecesi ve histopatolojik grade arasında istatistiksel olarak anlam bulunamamıştır $(p>0,05)$. Yine hastalığın evresi ile tümör boyutu, miyometrium invazyon derecesi ve histopatolojik grade arasında da istatistiksel olarak anlam bulunamamıştır ( $p>0,05)$. Zaten tüm hastalarımıza evreleme cerrahisi yapılmış ve erken bulgu vermesi nedeni ile hastalarımızın büyük kısmı erken evrede tanı almıştır.

Lenfovasküler alan invazyonu, endometrial kanserlerde nodal hastalığın belirteci olup, hastalığın tüm evrelerinde nüks ve ölüm için bağımsız bir risk faktörü kabul edilmektedir $(14,15)$. Evre 1 endometrium kanseri olgularında lenfovasküler tutulum olması yüksek ölüm oranlarıyla korele bulunmuştur (16). Peritoneal sitoloji FIGO 2009 evreleme sisteminden çıkarılmış ancak yapılan bazı çalışmalar sitoloji pozitifliği olan hastalarda sağkalım oranlarının daha düşük olduğunu göstermiştir (1720). GOG çalışmasında pozitif sitoloji varlığında hastaların ölüm riskinin 3 kat arttığı saptanmıştır (20). Bizim hastalarımızda lenfovasküler alan tutulumu \% 17,1 ve bunların \% 71'i evre 1-2 olup \%36' sında lenf nodu metastazı bulunmaktaydı. Hem lenfovasküler alan tutulumu hem peritoneal sitoloji ile lenf nodu metastazı ve evre arasında istatistiksel olarak anlam mevcuttu ( $p>0,05)$. Çalışmamızın bazı kısıtlamaları bulunmaktadır. Hasta grubumuzun büyük kısmının erken evre endometrium kanseridir ve çalışmamız retrospektif olarak düzenlenmiştir.

Sonuç olarak; Endometrium kanseri en sık görülen jinekolojik kanser olup, erken dönemde bulgu vermesi sonucu genellikle erken evrede yakalanmaktadır. Hastalığın riskini değerlendirmede tümör boyutu, miyometrial invazyon derinliği, histopatolojik grade kullanılmaktadır. Lenfovasküler alan tutulumu, sitoloji pozitifliği de ileri evre hastalık ile ilişkili bulunmuştur. Ancak özellikle yüksek invazyon dereceli hasta sayının daha fazla olduğu çalışmalar risk belirlemede daha faydalı olacaktır.

Çıkar Çatışması: Çalışmada herhangi bir çıkar çatışması yoktur.

Finansal Çıkar Çatışması: Çalışmada herhangi bir finansal çıkar çatışması yoktur.
Yazışma Adresi: Emine Türen Demir, Necmettin Erbakan Üniversitesi, Meram Tıp Fakültesi, Kadın Hastalıkları ve Doğum Anabilim Dalı, Konya, Türkiye

Telefon: 03323236415

E-mail: eturen1@hotmail.com

\section{KAYNAKLAR}

1. Siegel RL, Miller KD, Jemal A. Cancer statistics. Cancer J Clin 2019;69(1):7-34.

2. https://hsgm.saglik.gov.tr/tr/kanser-istatistikleri

3. Cancer facts and figures. American Cancer Society, Atlanta, Georgia 2019 [https://www.cancer.org/content/dam/cancerorg/research/cancer-facts-and-statistics/annual-cancerfacts-and-figures/2019/cancer-facts-and-figures-2019.pdf]

4. Creasman WT, Odicino F, Maisonneuve P, et al. Carcinoma of the corpus uteri. FIGO 26th annual report on the results of treatment in gynecological cancer. Int J Gynaecol Obstet 2006;95 Suppl 1:S105-43.

5. Lee NK, Cheung MK, Shin JY, et al. Prognostic factors for uterine cancer in reproductive-aged women. Obstet Gynecol 2007;109(3):655-62.

6. Karlsson B, Granberg S, Wikland M, et al. Transvaginal ultrasonography of the endometrium in women with postmenopausal bleeding-a nordic multicenter study. Am J Obstet Gynecol 1995;172:1488-94.

7. Siegel RL, Miller KD, Jemal A. Cancer statistics. Cancer J Clin 2015;65:5-29.

8. Kurman RJ, Kaminski PF, Norris HJ. The behavior of endometrial hyperplasia. A long-term study of "untreated" hyperplasia in 170 patients. Cancer 1985;56:403-12.

9. Edmondson RJ, Crosbie EJ, Nickkho-Amiry M, et al. Markers of the p53 pathway further refine molecular profiling in highrisk endometrial cancer: A transportec initiative. Gynecol Oncol 2017;146:327-33.

10. Santaballa A, Matías-Guiu X, Redondo A, et al. SEOM clinical guidelines for endometrial cancer. Clin Transl Oncol 2018;20(1):29-37.

11. Mariani A, Webb MJ, Keeney GL, et al. Low-risk corpus cancer: Is lymphadenectomy or radiotherapy necessary? Am J Obstet Gynecol 2000;182:1506-19.

12. Schink JC, Miller DS, Lurain JR, et al. Tumor size in endometrial cancer. Cancer 1991;67:2791-4.

13. Vargas R, Rauh-Hain JA, Clemmer J, et al. Tumor size, depth of invasion, and histologic grade as prognostic factors of lymph node involvement in endometrial cancer: A SEER analysis. Gynecol Oncol 2014;133(2):216-20.

14. Zaino RJ, Kurman RJ, Diana KL, et al. Pathologic models to predict outcome for women with endometrial adenocarcinoma: The importance of the distinction between surgical stage and clinical stage--a gynecologic oncology group study. Cancer 1996;77(6):1115-21.

15. Dos Reis R, Burzawa JK, Tsunoda AT, et al. Lymphovascular space invasion portends poor prognosis in low-risk endometrial cancer. Int J Gynecol Cancer 2015;25(7):12929.

16. O'Brien DJ, Flannelly G, Mooney EE, et al. Lymphovascular space involvement in early stage well-differentiated endometrial cancer is associated with increased mortality. BJOG 2009;116:991-4.

17. Milosevic MF, Dembo AJ, Thomas GM. The clinical significance of malignant peritoneal cytology in stage 
endometrial carcinoma. Int J Gynecol Cancer 1992;2(5):22535.

18. Garg G, Gao F, Wright JD, et al. Positive peritoneal cytology is an independent risk-factor in early stage endometrial cancer. Gynecol Oncol 2013;128(1):77-82.

19. Saga $Y$, Imai $M$, Jobo $T$, et al. Is peritoneal cytology a prognostic factor of endometrial cancer confined to the uterus? Gynecol Oncol 2006;103(1):277-80.
20. Morrow CP, Bundy BN, Kurman RJ, et al. Relationship between surgical-pathological risk factors and outcome in clinical stage I and II carcinoma of the endometrium: A Gynecologic Oncology Group study. Gynecol Oncol 1991;40(1):55-65. 